\title{
Interruption in the supply of breathing gas during general anesthesia due to malposition of the vaporizer
} -A case report-

\author{
Hyo Jin Kim, and Mi Woon Kim
}

Department of Anesthesiology and Pain Medicine, College of Medicine, Dongguk University, Gyeongju, Korea

We report a case of interruption in the supply of breathing gas during general anesthesia caused by malposition of the Drager Vapor $2000^{\circledR}$ vaporizer, which was accidentally tilted and lifted off the Selectatec manifold of the anesthesia machine. Because the patient was an 1-month-old infant, we couldn't check if he had experienced awareness with recall. We emphasize the importance of checking the anesthetic vaporizer after mounting it on the back bar of the anesthesia machine. (Korean J Anesthesiol 2010; 59: 270-274)

Key Words: Gas leak, Selectatec, Vaporizer.

The Selectatec, a vaporizer mounting system designed by Datex-Ohmeda has several advantages over permanent mounting systems. It allows the vaporizer to be easily mounted, removed, and replaced, even during a case. The anesthesia machine can have fewer mounting locations, allowing a more compact machine. If malignant hyperthermia is suspected, the vaporizers can be removed. This gives better results than if the vaporizers remain on the machine in the off position [1]. However, there are some disadvantages of this mounting system. Partial or complete obstruction to gas flow from problems with the mounting system has been reported. There have been several reports of leaks from the junction between a vaporizer and the Selectatec block, with risks of hypoventilation, rebreathing, oxygen dilution, and awareness, depending on the breathing system and the manner of ventilation [2].
We experienced a case in which the Drager Vapor $2000^{\circledR}$ vaporizer was incorrectly mounted on the Selectatec manifold of the Datex-Ohmeda Aestiva ${ }^{\circledR} / 5$ compact plus anesthesia machine, which caused a gas leak and interruption in the supply of breathing gas.

\section{Case Report}

An 1-month-old, $4 \mathrm{~kg}$, male patient was admitted for left inguinal herniorrhaphy. His prenatal and birth history were uncomplicated and past medical history and family history were unremarkable. The physical examination was unremarkable and preoperative laboratory tests were within normal limits. His vital signs were pulse rate: 160 beats per minute, respiratory rate: 42 per minute, and body temperature: $37.3^{\circ} \mathrm{C}$. He was not

Received: September 29, 2009. Revised: 1st, October 26, 2009; 2nd, December 28, 2009. Accepted: January 21, 2010.

Corresponding author: Mi Woon Kim, M.D., Department of Anesthesiology and Pain Medicine, College of Medicine, Dongguk University, Seokjang-dong, Gyeongju 780-714, Korea. Tel: 82-54-770-8271, Fax: 82-54-770-8378, E-mail: swankim7@yahoo.co.kr

(c) This is an open-access article distributed under the terms of the Creative Commons Attribution Non-Commercial License (http:// creativecommons.org/licenses/by-nc/3.0/), which permits unrestricted non-commercial use, distribution, and reproduction in any medium, provided the original work is properly cited. 
premedicated. On the operating table, we began intraoperative monitoring including electrocardiography, blood pressure, and pulse oximeter. Ketamine $10 \mathrm{mg}$ and glycopyrrolate $0.05 \mathrm{mg}$ were intravenously administered for induction of anesthesia. Assisted ventilation with enflurane 5 vol\% and oxygen $5 \mathrm{~L} / \mathrm{min}$ was performed without any problem by a facemask attached to a Mapleson D circuit, which was connected to the auxiliary common gas outlet of a Datex-Ohmeda Aestiva ${ }^{\circledR} / 5$ compact anesthesia machine. Atracurium $5 \mathrm{mg}$ was administered. After muscle relaxation had been sufficiently achieved, endotracheal intubation was performed using a standard $4.5 \mathrm{~mm}$ internal diameter uncuffed tracheal tube. There were no signs of a leak around the tube. For the first 5 minutes, enflurane 2.5 vol\%, nitrous oxide $2 \mathrm{~L} / \mathrm{min}$, and oxygen $2 \mathrm{~L} / \mathrm{min}$ were used for maintenance of anesthesia. Sevoflurane was planned to be used for rapid awakening after the surgery. From the anesthesia machine, The Tec 7 enflurane vaporizer was removed from the anesthesia machine, and in its place, a sevoflurane vaporizer (Drager Vapor ${ }^{\circledR} 2000$ ) was mounted. The Mapleson D circuit was replaced with the semi-closed circuit and methancial ventilation with the anesthesia ventilator was started.

After about 1 minute, the oxygen saturation dropped to below $90 \%$. At this stage, the partial pressure of end-tidal carbon dioxide and heart rate were higher than before switching to sevoflurane. Partial pressure of end-tidal carbon dioxide was at least $60 \mathrm{mmHg}$, and the heart rate was $160-170$ beats per minute. Immediately, we switched to manual ventilation. The reservoir bag was not filling sufficiently, therefore, the APL valve was adjusted and the oxygen was flushed, so that the reservoir bag would fill while we raised the respiratory rate and tidal volume. Then partial pressure of end-tidal carbon dioxide slowly fell to 50-60 mmHg. Oxygen saturation was maintained at a minimum of $90 \%$, but the capnographic waveform showed an inhaled carbon dioxide concentration greater than zero, and it seemed as if inhalation of exhaled gas caused an increase in inspired carbon dioxide. Even after adjusting the APL valve, the reservoir bag did not properly fill. We continued oxygen flushing to fill the reservoir bag to supply gas while checking the machine. We checked the carbon dioxide absorber and the unidirectional valve, which were working normally. The breathing circuit was observed, but no leakage was found. The pressure of the gas supplied by the central piping system was in the normal range. The flowmeter was also working normally. To check if a circuit inside the anesthesia machine was leaking, a positive-pressure leak test was performed, and there weren't leaks. The breathing circuit was replaced with the Mapleson D circuit again and the reservoir bag was still filled only by oxygen flushing. Five minutes of checking the anesthesia machine did not help in finding the cause, so the anesthesia machine was replaced with another anesthesia machine with a sevoflurane vaporizer mounted. Then breathing gas was supplied with ease. The patient's oxygen saturation was $98 \%$, and partial pressure of end-tidal carbon dioxide was maintained at $28-32 \mathrm{mmHg}$. The surgery was safely completed.

After the surgery, the former anesthesia machine was carefully inspected. The sevoflurane vaporizer was found to have slightly tilted to one side. When seen from the front, the right side of the sevoflurane vaporizer appeared to be slightly lifted. After attaching to the test lungs, oxygen $5 \mathrm{~L} / \mathrm{min}$ was delivered, but the test lungs had barely inflated, so we could see that there was an interruption of the gas flow.

We remounted the vaporizer properly and attached the test lung. The test lung inflated, and we were able to see proper gas flow. We then reproduced the same situation. After mounting the vaporizer, when seen from the front, the right side of the vaporizer was raised, as in the present case (Fig. 1). The locking lever of the sevoflurane vaporizer was turned back, allowing for the vaporizer to be used. The vaporizer's concentration control dial was set to 3.0 vol\% and oxygen $2 \mathrm{~L} / \mathrm{min}$ and nitrous oxide $2 \mathrm{~L} / \mathrm{min}$ were delivered, but the test lung barely inflated. Around the vaporizer, the smell of the anesthetic gas could be slightly smelled. The carbon dioxide/anesthetic agent sampling tube (Datex Capnomac Ultima ${ }^{\mathrm{TM}}$ Datex-Ohmeda, Finland) was disconnected from the breathing system and placed around the connection between the vaporizer and the manifold. The anesthesia monitor (Datex-Ohmeda $\mathrm{S} / 5^{\mathrm{TM}}$ Anesthesia Monitor, GE Healthcare, USA) showed that nitrous oxide and sevoflurane were detected. The vaporizer was tilted at a different angle and secured, and the gas concentration was measured around the vaporizer and at the Y connector. Depending on the angle of the tilt, there were large differences in the concentrations of sevoflurane, oxygen, and nitrous oxide. Between adjacent vaporizers, the interlock system worked fine. Therefore the

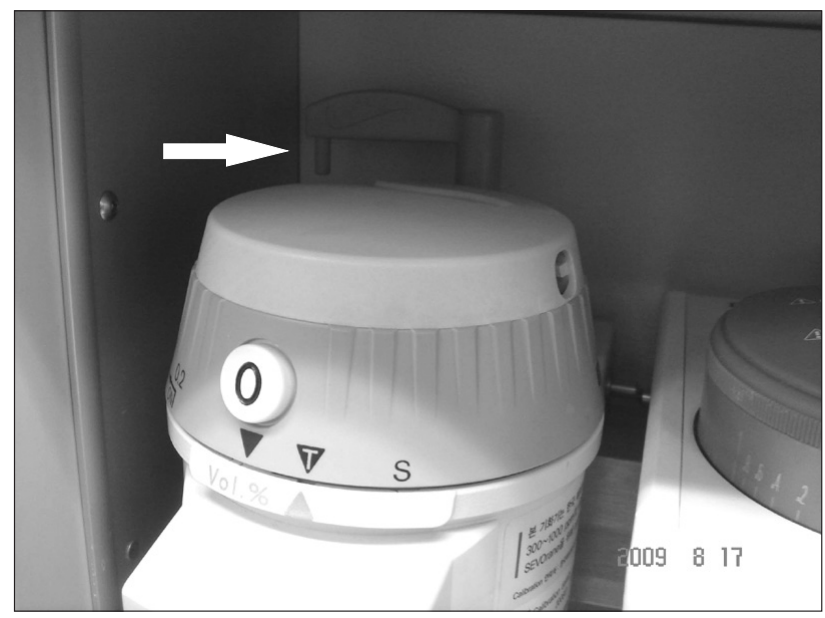

Fig. 1. Despite malposition of Drager Vapor $2000^{\circledR}$ vaporizer on the back bar, locking lever (white arrow) can be in working position. 
isoflurane vaporizer's concentration control dial on the side couldn't be turned to the on position. The anesthesia machine was reinspected by specialists on anesthesia machines, but they did not find anything functionally wrong. We trained anesthesia residents not to replace the vaporizer during surgery and to pretest the anesthesia machine thoroughly.

\section{Discussion}

There are 2 types of vaporizer mounting systems: permanent mounting and detachable mounting. Detachable mounting systems are the standard on most anesthesia machines. They allow the vaporizer to be mounted and removed without the use of tools. The Selectatec system and a Plug-in system from Drager Medical are widely-used detachable mounting systems. The Selectatec system consists of a pair of port valves for the positioning of each vaporizer (Fig. 2). Each vaporizer has a special mounting bracket (containing two plungers) which fits over the port valves. Often times, vaporizers cannot be exchanged between the Selectatec and Plug-in systems. However, the Drager Vapor $2000^{\circledR}$ can be compatible with various mounting systems, depending on types of mounting brackets. In the present case, the Vapor $2000{ }^{\circledR}$ had the mounting bracket Plug-In S 2000 adapter, which is suitable for the Selectatec system.

The Vapor $2000^{\circledR}$ of the present case has a locking lever, which locks the vaporizer in place so that it does not move or separate from the manifold. When it is not locked, the lever is engaged in the concentration control dial, so that it is impossible to turn on the concentration control dial. Only after swinging the locking lever clockwise 90 degrees to secure the vaporizer on the manifold, the concentration control dial can be free from the locking lever and turned on. The weight of the vaporizer and an O-ring around each port valve creates a seal between the mounting system and the vaporizer. When the vaporizer is turned on, the two plungers move downward, opening the

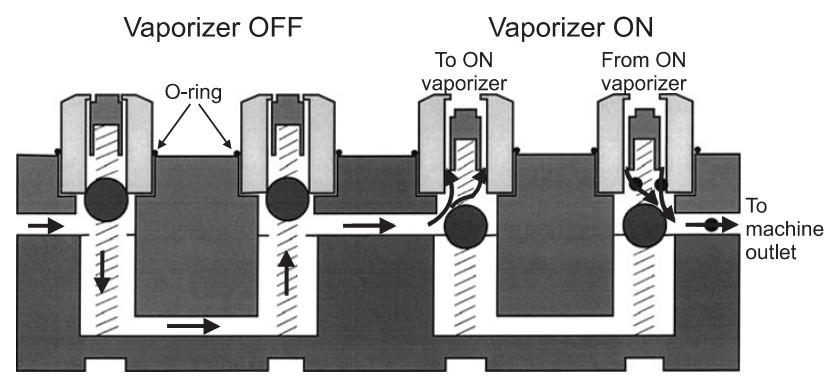

Fig. 2. Selectatec mounting system. When a vaporizer is mounted and turned on, two plungers push the valves down so that gas passes through the vaporizer. If the mounting position is empty or the vaporizer is turned off, the gas passes directly through the mounting system. valve ports and connecting the vaporizer into the fresh gas flow. When the vaporizer is turned off, it is isolated from the fresh gas flow.

There are three reported cases of anesthetic vapor leakage from unlocked vaporizers [3,4]. In two of them, awareness with recall was identified after surgery [4]. In those cases, Penlon Sigma Delta Anesthetic vaporizers were used and even when the locking lever was not locked, it was impossible to turn on the concentration control dial. On the other hand, Drager Vapor $2000^{\circledR}$ vaporizers and Tec 7 vaporizers' control dials cannot be turned unless the locking lever is locked, increasing their safety. In the present case, however, although the vaporizer was not properly fitted on the Selectatec manifold, the locking lever turned, and the concentration control dial was on. When the incident was reproduced, sevoflurane and nitrous oxide were detected near the vaporizer, suggesting a port valve opening and the leak of fresh gas containing anesthetic vapor, despite the malposition of the vaporizer.

A leak from a vaporizer or its mount should be suspected if a vaporizer appears to require filling with unusual frequency, if an odor can be detected, or if there is a loss or reduction in the fresh gas flow into the breathing system after the vaporizer is turned on [1]. When a gas leak is suspected near the vaporizer, a carbon dioxide/anesthetic agent sampling tube can be placed near the vaporizer to check if there is a leak [5]. The effects of a leak on a vaporizer will depend on the size and location of the leak and whether or not there is a check valve at the vaporizer outlet [1]. In addition to affecting the fresh gas composition and flow, leaks may pollute the operating room air. With a leak in a vaporizer or its mount, the machine will often function normally until the vaporizer is turned on. At that point, fresh gas flow from the machine will be lost through the leak, and the total flow will be reduced. The leak may contain little or no vapor, especially if it is in the mounting mechanism. In adults, the minimum alveolar concentration (MAC) of sevoflurane is 1.71 , and $\mathrm{MAC}_{\text {awake }}$ is $0.5 \mathrm{MAC}$. However, the MAC of a 1-monthold baby is higher than of an adult, so the possibility that the patient in the present case may have experienced awareness with recall is very high, though not provable. If there was a monitoring method for measuring the intraoperative anesthetic depth, it would have helped. However, at the present, there are still no reliable devices for monitoring anesthetic depth in infants, as in our case [6].

Although partial pressure of end-tidal carbon dioxide technically does not clearly show alveolar carbon dioxide concentration in infants, especially when using the Mapleson circuit, as in our case [7], we suspect that hypercapnia occurred, considering the partial pressure of end-tidal carbon dioxide and the capnographic waveforms. Because the reservoir bag did not fill properly and the oxygen flush bypassing the 
vaporizer was able to fill the respiratory bag, it was assumed that hypoventilation or rebreathing likely occurred from the reduction in the fresh gas flow, which lead to hypercapnia and low oxygen saturation on the pulse oximeter. Before replacing the vaporizer, the anesthesia machine worked fine with adequate fresh gas flow and a supply of oxygen. Therefore, although the gas supply was poor after having replaced the vaporizer, none of the features usually associated with hypercapnia were apparent during anesthesia: the color of the blood in the surgical field was normal; there was no increase of a wound bleeding or oozing; peripheral vasodilatation was not visible; and there was no arrhythmia, except for the tachycardia, which had been present from induction. When the above situation was re-enacted, after the breathing circuit and reservoir bag were filled and the gas supply was interrupted during manual ventilation, abnormality in the reservoir bag could soon be sensed. However, there was hardly any change in the amount of air in the bellow of the anesthetic ventilator within the first 1 minute of the mechanical ventilation. Afterwards, some air was lost. The initially set tidal volume of 44-45 ml could be supplied for over 3 minutes. In clinical practice in a normal situation without a leak, even if the ventilator of the anesthesia machine sets the tidal volume at the constant rate, it is said that each respiratory cycle can have a difference in ventilation by dozens of $\mathrm{ml}$ [8]. It is difficult to immediately notice problems when the tidal volume is small in mechanical ventilation.

There are several items to be checked before using a vaporizer after mounting. Firstly, check that the vaporizer for the required volatile agent is fitted correctly to the anesthesia machine and that any back bar locking mechanism is fully engaged [9]. Secondly, check that the vaporizer is not tilted [10]. When the top of the vaporizer is seen from the side, see if each vaporizer is placed horizontally. If the vaporizers are all the same model, their heights must be the same. When some vaporizers are tipped sufficiently, there is the danger of leakage of anesthetic vapor, as happened in the present case. In addition, liquid from the vaporizing chamber may get into the bypass or outlet. If this occurs, a high concentration will be delivered when the vaporizer is first used. If a Vapor $2000^{\circledR}$ is operated at an angle of more than 30 degrees with the control dial not at the T setting, uncontrolled concentrations may occur [11]. However, in the present case and reenactment, it did not appear to have tilted more than 30 degrees. Thirdly, check that only one vaporizer can be turned on at a time. Fourthly, the vaporizer is located in the low pressure circuit from the flow control valves to the common gas outlet, so a leak test on the low pressure circuit must be taken. Most Datex-Ohmeda machines, including Aestiva, have a check valve, which is located just upstream of each machine's fresh gas outlet and separates the low pressure circuit from the breathing circuit, so positive-pressure leak test does not work in detecting vaporizer leaks. Instead, negativepressure leak test should be performed. In a negative-pressure leak test, a suction bulb is attached to the common gas outlet and squeezed. One must check to see if the suction bulb can stay squeezed for at least 10 seconds [12]. Even in Drager machines which do not have check valves, negative-pressure leak tests are more sensitive than positive pressure leak tests in finding low-pressure circuit leaks. The low-pressure circuit leak test should be performed daily, and each time the vaporizer is changed, performing the test is advised [13]. Many newer anesthesia workstations are capable of performing self-testing procedures, which, in some cases, may eliminate the need for the conventional negative-pressure leak testing. However, it is of importance that anesthesia care providers understand that these self-tests may not detect internal vaporizer leaks on systems with add-on vaporizers. For the self-tests to determine whether an internal vaporizer leak is present, the leak test must be repeated with each vaporizer sequentially while its concentration control dial is turned to the on position. When a vaporizer's concentration control dial is set in the off position, it may not be possible to detect even large internal leaks. Even after a proper preuse check, if anything is pushed under the vaporizer and the vaporizer is lifted even slightly from its mount, a leak may occur.

We experienced a case where the vaporizer was not correctly fitted to the back bar of the anesthesia machine and the flow of fresh gas containing the anesthetic agent was interrupted. The same situation as the original event could be reenacted after we inspected the vaporizer.

We were alerted that human error can reoccur, and anesthetic equipment, including the vaporizer, should not be replaced during a case, if possible. Whenever a vaporizer is mounted on an anesthesia machine, a thorough checkout should be performed.

\section{References}

1. Brown B, Dernoski N, Connors-Dovetail M. Vaporizers. In: Understanding Anesthesia Equipment. 5th ed. Edited by Dorsch JA, Dorsch SE: Philadelphia, Lippincott Williams \& Wilkins. 2008, p 181.

2. James RH. Defective Selectatec O-rings. Anaesthesia 1995; 50: 184-5.

3. Lee SY, Suh SH, Cho JH, Lim JA, Lee KM, Woo NS. An unexpected vapor leakage from unlocked vaporizer (Penlon Sigma Delta Anesthetic Vaporizer): a case report. Korean J Anesthesiol 2006; 51: 230-2.

4. Kim KH, Cho SY, Kim KN, Shim JH, Jeon WJ, Yeom JH, et al. Awareness during general anesthesia due to the unlock position of the vaporizer: a report on two cases. Korean J Anesthesiol 2009; 56: 693-7. 
5. Bolton P, Brock-Utne JG, Zumaran AA, Cummings J, Armstrong D. A simple method to identify an external vaporizer leak (the "SNIFF" method). Anesth Analg 2005; 101: 606-7.

6. Pietrini D, Piastra M, Lamperti M, Ingelmo PM. New trends in pediatric anesthesia. Minerva Anestesiol 2009; 75: 191-9.

7. Shin CM, Park JY, Lee TI. Comparison of arterial carbon dioxide tension and end-tidal carbon dioxide tension in infants and children. Korean J Anesthesiol 1991; 24: 490-5.

8. Seo IS, Im SG, Lee SM. Proper respiratory rate determination during controlled ventilation in infants under general anesthesia. Korean J Anesthesiol 2004; 46: 186-90.

9. Association of Anaesthetists of Great Britain and Ireland. Checking anaesthetic equipment. London, Association of Anaesthetists of Great Britain and Ireland, 2004.

10. Lee JR, Kim J, Ahn W. A standard and widely-usedpre-anesthetic checklist in Korea. [Internet]. Seoul: Seoul National University Hospital, 2006. Available from http://vam.anest.ufl.edu/koreanchecklist.html.

11. Drager Medical: Drager Vapor ${ }^{\circledR} 2000$ anesthetic vaporizer instructions for use. Lübeck, Drager Medical AG \& Co. KGaA. 2005, p 30 .

12. Brockwell RC, Andrews JJ. Anesthesia apparatus checkout recommendations. In: Miller's anesthesia. 6th ed. Edited by Miller RD: Philadelphia, Elsevier Churchill Livingstone, Inc. 2005, pp 315 6.

13. Sub-Committee of American Society of Anesthesiologists Committee on Equipment and Facilities. Recommendations for preanesthesia checkout procedures. Park Ridge, American Society of Anesthesiologists. 2008. 